\title{
Philosophy of the Performing Arts
}

\section{A book review}

Author: David Davies

Publisher: Wiley-Blackwell

Release Date: 2011

Number of Pages: 248

Jakub Ryszard Matyja

University of Huddersfield,

Polish Academy of Sciences

jrmatyja[]gmail.com

Received, accepted and published winter 2014/2015.

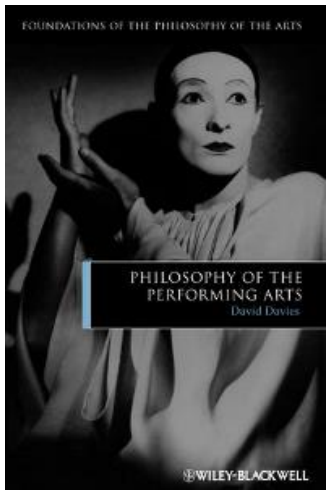

David Davies's Philosophy of the Performing Arts is a great and informative book, written in a remarkably clear style, definitely worth recommending this to both professionals and graduate students, since reading it requires background knowledge.

Accordingly, in his book, following the recent interests of philosophical aesthetics in the philosophy arts, Davies provides the reader with a throughout discussion of artistic performances that are considered as artworks in their own right. Such approach is thus distinctive from the framework of so-called "Classical Paradigm" (discussed in Part I of the book, see below), based on the assumption that classical music provides us with a model for performing arts as a whole. The author establishes the framework for further explorations (Part II), while bringing our disanalogies between performances of classical music and various other kinds of artistic performances. Thus, in his book Davies aims to identify, explore, clarify and account on the range of philosophical questions arising when one reflects on the nature of performing arts and our involvement with it.

Chapter 1 focuses on the nature of artistic performance as such, while aimimg to distinguish performance from mere action. Here Davies draws on the classical works of Beardsley (1982) or Dickie (1974) and others, while providing 
the analytic distinction between performances as works and performances in work. In the case of performance, argues Davies, the agent is consciously guided in his/her actions by his/her expectations as to how these actions would be judged by an indented audience evaluating it due to certain criteria. He then goes distinguishing artistic performances from other performances. According to the author, something counts as an artistic performance if it makes perceptually manifest to receivers qualities that bear upon the appreciation of work of art in certain, specified ways. Accordingly, Chapter 2 of the book explores the range of Classical Paradigm, accounting interestingly on the Type Theories of performable works (referring here to type / tokens distinction), while introducing and discussing Sonicism, Instrumentalism and Contextualism or Fictionalism among others. In Chapter 3 of his book, Davies aims to accounts on the following philosophical question: Can performance works share artistic performances properties with their performances? These leads him, in turn, to the discussion of famous Nelson Goodman's argument from his "Languages of Art" (1974) on the possibility of divorcing work of art from the history of its production. Chapter 4 offers an account on the issue of authenticity in musical performance. Davies discusses and accounts here for the works of Stephen Davies, James Young and Peter Kivy. In Chapter 5 the author of Philosophy of the Performing Arts, the author discusses the challenges to the Classical paradigm in music. Interestingly, apart from focusing on classical music, Davies goes into considerations on jazz, rock and non-western music. In this particular chapter he focuses on the works of such people as Andrew Kania or Theorodre Gracyk. Chapter 6 of the book, focuses on the scope of Classical paradigm, including theatre, dance and literature.

The second part of the book, starting from Chapter 7 begins with the discussion of spontaneous performances like Keith Jarrett's famous The Köln Concert from different perspectives. In the course of the book, as I have mentioned above, Davies distinguishes two ways in which artistic performances are distinguishable from other performances. He does so in two ways. Firstly, he suggests that what is is like to appreciate something as a work of art solely in terms of the kind of regard that is required to determine a work's artistic content. This is necessary, Davies claims, in virtue of the distinctive ways in which artworks articulate their contents. Secondly, the author distinguished two ways in which a performance can qualify as an artistic performance by manifesting qualities that bear in this way upon the appreciation of a work of arts. The performance may itself be an artwork, claims Davies, when the actions of the performer being the artistic vehicle through which the arstitcit content of the work is articulated. He dubs this kind of performance "performance-work", and Keith Jarrett's concert can be counted as an instance of it. Accordingly, Davies dubbed the case in which performance is something else that is an artwork "work-performance". Chapter 8 is focused on improvisation and rehearsal. Davies discussed three models of improvisation (improvisation 
on a theme, improvisational composition and pure improvisation). The next important issue in this chapter concerns the recording of improvisational musical piece, including rock musical performances. Chapter 9 of the book impressed me the most, since it tackles the issues of embodied cognition in terms of performance art. Davies shortly discusses the relation between performer and the audience in terms of mirroring processes supported by bodily perceptual and motor capacities and human mirror neuron system, recently discussed by various researchers. Importantly here, Davies discusses the works of Richard Shustermann, among other authors. I feel that Philosophy of Performing Arts would greatly benefit from extending this chapter a bit, since it tackles recently developing connections between philosophy of art and neuroscience. Finally, in the concluding Chapter 10, the author summarizes his argumentation and presents further philosophical questions posed by philosophy of performing arts. Moreover, the last chapter of Davies's fine book, considers some performances that occur in artistic context, but which status as artistic is either work-performance or performance-work, in the sense introduced above. He discusses the works of artists like Vito Acconci, Joesph Beuys and Laurie Anderson.

To conclude, David Davies' book is a brilliant and clearly written analysis of current debates on performing arts, that presents vividly how interesting and worth investigating this field is. Written in a engaging manner, Philosophy of the Performing Arts is definitely a thought-provoking study that is worth recommending for both inexperienced and experienced researchers. It is so, by being a lovely example of aesthetics done in the Anglo-American philosophical tradition.

Acknowledgement: Jakub Ryszard Matyja's involvement in this project was financed by the resources of the National Science Centre (NCN), granted under decision number DEC-2011/03/N/HS1/01703.

\section{References}

Beardsley, M.C. 1982. The Aesthetic Point of View. Ithaca, NY: Cornell University Press.

Dickie, G. 1974. Art and the Aesthetic: An Institutional Analysis. Ithaca, NY: Cornell University Press.

Goodman, N. 1974. Languages of Art. Hackett Publishing Company. 